\title{
O PERCURSO DISCURSIVO DA CIÊNCIA DA INFORMAÇÃO NO BRASIL: ANÁLISE DOS PERIÓDICOS CIÊNCIA DA INFORMAÇÃO E PERSPECTIVAS EM CIÊNCIA DA INFORMAÇÃO EM 1970, 1980 E 1990
}

\author{
THE DISCURSIVE PATH OF INFORMATION SCIENCE IN BRAZIL: ANALYSIS OF JOURNALS \\ CIÊNCIA DA INFORMAÇÃO AND PERSPECTIVAS EM CIÊNCIA DA INFORMAÇÃO IN 1970, 1980 \\ AND 1990
}

\author{
Ana Laura Silva Xavier \\ Mestranda em Ciência da Informação - UNESP \\ analaura.sx@gmail.com \\ Mariana da Silva Caprioli \\ Doutoranda em Ciência da Informação - UNESP \\ mariana.caprioli@gmail.com \\ Larissa de Mello Lima \\ Doutoranda em Ciência da Informação - UNESP \\ larissalima.unesp@gmail.com \\ João Batista Ernesto de Moraes \\ Doutoro em Estudos Literários \\ Professor do PPGCI-UNESP \\ prof.joao@gmail.com
}

Recebido em: 16-04-2019

Aceito em: 14-06-2019

\begin{abstract}
Resumo: A partir da década de 1970, a Ciência da Informação se desenvolve em território brasileiro constituindo assim um percurso conceitual, discursivo e histórico passível de ser confrontado pelos pressupostos teóricos e metodológicos da Análise do Discurso de matriz francesa. No presente trabalho o problema pode ser definido através da seguinte pergunta: "Qual o discurso criado pela Ciência da Informação em suas décadas inaugurais?" Para respondê-la o objetivo é mostrar o delineamento que foi realizado do percurso conceitual e discursivo da área no Brasil nas décadas de 1970 , 1980 e 1990. Como resultado foi possível verificar que nas três décadas legitima-se a discrepância entre as definições acerca da área, ou seja, não há um equilíbrio epistemológico acerca do que seria a Ciência da Informação mas sim, dois polos de atuação: o que encara a Ciência da Informação enquanto Interdisciplinar, sendo mais teórico, e o polo que mostra a responsabilidade da Ciência da Informação na atualidade, sendo este mais concreto.
\end{abstract}

Palavras-chave: Análise comparativa; Análise qualitativa; Epistemologia da Ciência da Ciência da Informação; Publicações seriadas; Ciência da Informação

\begin{abstract}
From the 1970s decade, Information Science developed in Brazilian territory, constituting a conceptual, discursive and historical course that could be confronted by the theoretical and methodological assumptions of French Discourse Analysis. In the present work the problem can be defined by the following question: "What is the discourse created by Information Science in its inaugural decades?" To answer it the objective is to show the delineation that was carried out of the conceptual and discursive course of the area in Brazil in the 1970s, 1980s and 1990s. As a result, it was possible to verify that in the three decades the discrepancy between the definitions about the area is legitimate, that is, there is no epistemological balance about what would be Information Science, but two poles of action: what the Information Science considers as Interdisciplinary, being more theoretical, and the pole that shows the responsibility of Information Science in the present time, being this more concrete.
\end{abstract}

Keywords: Comparative analysis; Qualitative analysis; Epistemology of Science of Information Science; Serial publications; information Science 


\section{INTRODUÇÃO}

O desenvolvimento da área em Ciência da Informação no Brasil ocorre a partir da criação do curso de mestrado na década de 1970 com a participação do Instituto Brasileiro de Bibliografia e Documentação IBBD vinculado ao Conselho Nacional de Pesquisas. Em decorrência, dois anos depois surgem os primeiros periódicos na área: Ciência da Informação, publicado pelo IBBD e Universidade Federal do Rio de Janeiro UFRJ; e a Revista da Escola de Biblioteconomia da UFMG, editado pela Universidade Federal de Minas Gerais - UFMG e que posteriormente passa a ser denominado de Perspectivas em Ciência da Informação. A fundação do IBBD ocorre em 1954, como órgão do Conselho Nacional de Pesquisas - CNPq inspirado pela Unesco com intermediação da Fundação Getúlio Vargas - FGV.

O marco nítido da Ciência da Informação no Brasil é a criação do curso do mestrado, porém, anteriormente já existiam movimentos que articulavam para o "aparecimento" da área. Oddone (2006) aponta que a Ciência da Informação não surgiu no Brasil, em terreno estéril. Ao contrário, sua emergência ocorreu em um espaço onde outros saberes já estavam construídos, deixando vestígios na concepção da nova disciplina e na formulação de suas estratégias profissionais e acadêmicas.

Desde 1970 portanto, a área produz um percurso marcado por características históricas, políticas e institucionais que desencadearam o desenvolvimento da área de modo que pode-se indagar: "[...] qual o discurso criado pela Ciência da Informação em suas décadas inaugurais? Entende-se discurso como ponto de interação entre os fenômenos linguísticos e os processos ideológicos” (BRANDÃO, 2004, p. 11).

Buscou-se na Análise do Discurso de matriz francesa um aporte teórico e metodológico que evidencie os jogo de enunciados, posições ideológicas e sujeitos produtores (CAPRIOLI, 2016) existentes no discurso da Ciência da Informação.

Constituiu-se como objetivo geral delinear o percurso conceitual e discursivo da Ciência da Informação no Brasil durante as décadas de 1970, 1980 e 1990 por meio dos periódicos da área. Desta forma, pode-se entender não apenas o "o que é dito", mas sim o "como é dito" da Ciência da Informação.

Acredita-se ser importante retomar brevemente o contexto histórico pelo qual a França passava para contextualizar os mecanismos que tornaram possível dar importância para os estudos centrados no sujeito da linguagem e por conseguinte, discurso. Michel Pêcheux, filósofo de formação, começa a realizar uma forte ligação entre a Filosofia e as Ciências Sociais a partir de uma série de estudos centrados na língua (HENRY, 1997)

Tal perspectiva se liga com o movimento que começa a irromper na França de negação ao estruturalismo em meados da década de 1960. Buscava combater o excesso de formalismo e padronização dos elementos da linguagem tratados, por influência dos postulados de Saussure, de maneira estrutural.

Em “curso de linguística geral” Saussure afirma que língua e fala são diferentes, possuindo relação de oposição. Para Saussure a língua é o conjunto de signos estruturados, o todo, que uma comunidade utiliza para se comunicar, ou seja, é algo coletivo e social. Já a fala ele denomina como algo individual, particular, é a maneira como as pessoas usam a língua. Embora diferentes, elas se completam, são dependentes uma da outra. 
A língua, para que possa existir, se estabelecer, precisa de falantes. Desta maneira, a fala também precisa de um modo para existir, um código, uma ferramenta. Saussure fez seu estudo sobre a língua, pois, segundo ele, era propícia para aprofundamento naquele momento, deixando a fala de lado (SAUSSURE, 1966)

Ao mesmo tempo em que deixou em segunda plano a fala, Saussure deixa aberto um campo de estudo rico e até então sem aprofundamento teórico.

Ao serem interligados estes fatores listados acima; o excesso de formalismo linguístico somado ao sujeito que conduz a fala sendo deixado em segundo plano, Pêcheux e seus seguidores criam a Análise do Discurso Francesa. O marco inicial da corrente teórica foi fixado no lançamento paralelo em 1969 da obra "Análise Automática do Discurso" de Michel Pêcheux, e da Revista Langages criada por Jean Dubois. (GREGOLIN, 2006; MAINGUENEAU, 1997).

Torna-se legítimo afirmar que eles possuíam um solo fértil para germinar teorias centradas no sujeito até então esquecido. Ele retoma, por exemplo, elementos da teoria do inconsciente coletivo de Lacan para dar conta de falar sobre o papel desempenhado pelo sujeito nos discursos.

Além disso são colocados em primeiro plano a questão da ideologia, ele afirma que "[...] a ciência é antes de tudo a ideologia com a qual rompe”. Para falar de ideologia ele retoma Louis Althusser, de quem foi aluno e a encara enquanto o que "[...] interpela os indivíduos enquanto sujeitos" (ALTHUSSER, 1998), sendo reflexo de uma representação entre a realidade e o sujeito. Seu percurso teórico e metodológico na análise do discurso Francesa é sustentada na pirâmide que busca articular o materialismo histórico com a teoria da ideologia, a linguística focando nos processos de enunciação, e a teoria do discurso que coloca em centro a teoria de determinação histórica dos processos semânticos. (ORLANDI, 1999)

Em contrapartida, neste momento entramos na noção sincrônica de tempo histórico para situar Michel Foucault na Análise do discurso de matriz Francesa.

Foucault nunca estabeleceu um conjunto de pautas sistemáticas ou instruções de como realizar sua análise do discurso, aspecto que entra em consonância com a própria atuação e coerência intelectual do autor: "Eu tomo cuidado de não ditar como as coisas deveriam ser" (FOUCAULT 1994, p. 288). Sem dúvida, isto não impediu que numerosos estudiosos e leitores de Foucault tenham identificado os passos metodológicos que ele utilizou em seus diferentes estudos, para extraí-los e distingui-los de outros métodos. Foucault sempre foi explícito e detalhado - pode-se até dizer metódico - com respeito a suas próprias obras, e isto permitiu criar uma escola de estudiosos. Como Niels Åkerstrøm Andersen afirma: "Foucault falhou fundamentalmente em um aspecto. Ele fundou uma escola de pensamento, embora a sua ambição explícita fosse a de não fazer isso" (ANDERSEN, 2003, p. 1).

Mutável e fluido como as categorias estudadas por Foucault, o método por ele utilizado - que será denominado por conveniência de análise do discurso - também variou em seus diferentes trabalhos. Assim, podem-se identificar, no mínimo, as variantes de análise arqueológica, análise genealógica, tecnologia de autoanálise (self-technology analysis) e análise dispositiva. 
Em todo caso ao menos uma coisa deve ser sublinhada: a análise do discurso assim entendida, não desvenda a universalidade de um sentido; ela mostra à luz do dia o jogo de rarefação imposta, com um poder fundamental de afirmação. Rarefação e afirmação, rarefação, enfim, de afirmação e não generosidade contínua do sentido, e não monarquia do significante. E agora os que têm lacunas de vocabulário que digam - se isso lhes soar melhor, que isto é estruturalismo. (FOUCAULT, 1972, p. 70)

Na passagem acima, Foucault (1972) destaca o fato do sentido não ser único, mas perpassado por camadas de validação que ao se cruzarem causam o impacto da rarefação, que, nada mais é do que a materialidade dos enunciados; estes, por sua vez, ao se relacionar, desembocam na multiplicidade de sentidos. A partir de então, surge o poder de afirmação de determinado sentido em detrimento de outro. Por trabalhar no limiar da oposição estrutural "rarefação/afirmação", defende-se do rótulo de estruturalista. Possenti (2009) afirma que Foucault é o autor que, ao ser associado à análise do discurso, mais se distancia da Linguística. Tal afirmação é corroborada pelo fato de ter frisado que seus estudos não se enquadravam enquanto estruturalistas, conforme comenta Fischer (2012, p 120): "[...] não deixa de ser curioso o quanto Foucault se empenhou em dizer, tanto nas inúmeras entrevistas que concedeu quanto nos seus livros, que não era um estruturalista e que deixassem de querer enquadrá-lo neste ou naquele rótulo.”

Ao negar o rótulo, ele deixa de lado um legado de discussões oriundas da linguística de Saussure que mudou os paradigmas das ciências humanas do século XX com a marcante presença do estruturalismo em suas dicotomias. Colocando em pauta outras maneiras de situar o discurso, temos a figura de Michel Pêcheux (1975; 1983), filósofo contemporâneo aos estudos de Foucault, que entende o discurso diante da perspectiva do acontecimento, da estrutura e da descrição, ou seja, o foco de Pêcheux é trabalhar estes três elementos em relação ao contexto, retomando a materialidade do enunciado. Este filósofo coloca em dúvida a situação do objeto discurso, ancora sua dúvida na perspectiva da opacidade do acontecimento, ou seja, para o referido autor, o enunciado, na análise do discurso, possui materialidade, porém tal materialidade está inserida na opacidade do acontecimento.

A opacidade do acontecimento caminha para o sentido, defendido por Pêcheux, de que a linguagem está sujeita a ambiguidades; uma série de sentidos dentro da matriz dos dizeres; sendo assim, o acontecimento é opaco na medida em que há um emaranhado de vozes que se cruzam refletindo formações ideológicas plurais. A estrutura e o acontecimento não possuem uma distinção estrita para Pêcheux, pois os considera sempre em relação à sua exterioridade, ou seja, a exterioridade da estrutura de determinado discurso em paralelo com a exterioridade do acontecimento de outro discurso acarreta na perspectiva do interdiscurso/memória discursiva.

Segundo Orlandi (1999, p. 89-90), "O interdiscurso é o conjunto do dizível, histórica e linguisticamente definido. Pelo conceito de interdiscurso, Pêcheux nos indica que sempre já há discurso [...]". Desta forma, situa-se o interdiscurso no limiar do que já foi dito sobre determinada enunciação e se repete ao longo do tempo.

Para Pêcheux, "toda formação discursiva dissimula, pela sua transparência de sentido que nela se constitui, sua dependência com relação ao "todo complexo dominante"” das formações discursivas. Pêcheux 
defende que o discurso é a união do acontecimento, da estrutura e da descrição, sob o viés que relaciona a língua com a ideologia. Torna-se interessante mostrar os pontos de convergência teórica entre Foucault e Pêcheux. É possível trabalhar tal perspectiva realizando um paralelo entre o conceito de "Interdição" em Foucault e "Formação discursiva" em Pêcheux. Em "A ordem do discurso", Foucault explica o conceito de interdição no limiar de uma espécie de pêndulo, ou seja, os dizeres são regulados pelo "poder dizer", como ele bem assinala "não se pode falar de tudo em quaisquer circunstâncias" (Foucault, 1996, p.9), ou seja, esse poder dizer é revestido de uma série de elementos que tornam legitimada a enunciação do autor, que nunca é neutro e carrega nesse dizer a perspectiva institucional.

Já Michel Pêcheux (1983) fala de maneira muito semelhante sobre essas amarras no dizer, conceituando como "formação discursiva"; para o autor, a formação discursiva determina o que pode ou não ser dito dentro de determinado contexto. É importante pontuar que Foucault também se utiliza do conceito de formação discursiva, mas o entende enquanto a posição tomada pelo sujeito do discurso para que ele possa materializar a sua enunciação.

Através do percurso conceitual acima descrito, tornou-se possível entender a multiplicidade de abordagens que o objeto discurso pode assumir. A vertente centrada nos postulados de Van Dijk (1972), denominada Análise Crítica do Discurso, busca analisar enunciações focando-se nos problemas sociais e mecanismos políticos da atuação discursiva. Pode-se dizer que a escola Francesa da Análise do Discurso e a análise crítica do discurso compartilham o olhar sob a dimensão textual discursiva enquanto uma ruptura com a materialidade linguística. A abordagem deste trabalho parte da teoria discursiva da Escola Francesa de Análise do Discurso.

\section{ANÁLISE DO DISCURSO NO CONTEXTO BRASILEIRO}

Para falar sobre a escola brasileira de Análise do Discurso é necessário percorrer os desdobramentos teóricos da obra de Michel Pêcheux no território brasileiro que, devido as suas características históricas, desenvolveu-se de maneira diferente daquela presente no território francês. Devido ao percurso da análise do discurso no Brasil, é possível dizer que ainda fala-se muito em Pêcheux.

A sua introdução no Brasil sofreu grande influência do regime militar, em 1964 até meados da década de 1980. Costuma-se dizer que, no final dos anos 70 e no início dos anos 80 , a análise do discurso foi instaurada no Brasil - mais especificamente na UNICAMP -, onde a professora Eni Pulcinelli Orlandi ministrava os primeiros cursos devido ao enfraquecimento pelo qual passava a ditadura militar nesse período. Ela pondera a respeito da análise do discurso no Brasil.

Análise de discurso institucionaliza-se amplamente - não sem algumas resistências, alguns antagonismos - e, com sua produção e alcance teórico, configura-se como uma disciplina de solo fértil, com muitas consequências tanto para a teoria como para a prática do saber linguístico. (ORLANDI, 1999, p. 9) 
O principal ponto é que, diferente do que aconteceu na França, acabaram por separar a análise dos textos, uma relacionada aos textos escritos e outra preocupada com a oralidade. No Brasil, a análise do discurso manteve o interesse em ambos os tipos de produções, dando uma sustentação diferente ao método e ao uso da mesma.

\section{DIÁLOGOS ENTRE ANÁLISE DO DISCURSO E CIÊNCIA DA INFORMAÇÃO}

A Análise de Discurso surge na França em meados de 1960 a partir do estruturalismo e se articula em torno da "escritura", da linguística, do marxismo e da psicanálise (MAINGUENEAU, 1997, p. 10). Já a Ciência da Informação emerge posteriormente à Segunda Guerra Mundial devido à revolução teórica e científica e a explosão informacional. Cordeiro (2004, p. 85) aponta que os dois campos evoluem a partir dos anos 1960 seguindo caminhos semelhantes se consideradas, ambas, como expressão de uma face da ciência pós- moderna.

A partir do pós Guerra, apresentam crises que são comparáveis e em sincronia apresentam trânsitos por várias espaços epistemológicos: do paradigma físico, ao paradigma cognitivo, daí ao social. Assim se descreve os passos da CI. Se bem que há quem diga que os modelos dos paradigmas já não se aplicam mais. Nem mesmo a epistemologia teria aplicação tão efetiva se comparada à arqueologia do saber. A Análise do Discurso visa realizar "[...] uma análise interna (o que este texto diz? como ele diz?) e uma análise externa (porque este texto diz o que ele diz?)" (GREGOLIN, 1995, P. 17).

Pode-se perceber, então, que Análise do Discurso e Ciência da Informação seguiram caminhos parecidos desde a criação Belkin e Robertson citados por Freire (1995) nos mostra que a primeira é constituída por um conjunto ou coleção de signos que foram estruturados de tal forma propositalmente ou propositadamente por um emissor que tem a intenção de mudar a imagem para o receptor, ou seja, se pensa em como o emissor pode estruturar seus pensamentos para que o receptor seja capaz de perceber a mensagem que o emissor desejava passar. O que se torna semelhante com o que a A.D.

Este estudo define-se como teórico, exploratório e documental e dividiu-se em três fases teórico metodológicas: a) Revisão bibliográfica da Análise do Discurso por meio dos autores como Brandão (2004), Foucault (1994), Gregolin (1995, 2006), Orlandi $(1999,2000)$ e Ciência da Informação através de Oddone (2006), Pinheiro (1997)

Além disso, foi de extrema relevância buscar compreender o diálogo possível entre Análise do Discurso e Ciência da Informação: Buschman (2010) e Freitas (2001, 2004, 2010).

A segunda fase teórico-metodológica consiste na recuperação e seleção dos artigos que viriam a compor o corpus de análise. Para tanto, foram acessados os sites dos periódicos Ciência da Informação e Revista da Escola de Biblioteconomia da UFMG no período de 1970 a 1999 que continham o termo "Ciência da Informação" no título, resumo e/ou palavras-chave. A escolha destes periódicos deve-se ao fato de ambos serem os primeiros da área. Quanto as décadas, escolheu-se estes períodos, pois buscou-se compreender o discurso da área em seus momentos iniciais. 
Por fim, na última fase teórico-metodológica realizou-se a análise dos artigos selecionados. A análise pautou-se em Orlandi (2000, p. 77) fundamentada em Pêcheux (1975) e sistematizado por Lima (2015, p. 19, grifo da autora):

"Primeiro tratamento de análise superficial":

Momento em que se tem um contato primário com a superfície linguística do texto. É também neste momento em que é exposto o elemento do arquivo, ou seja, o corpus que será submetido à análise.

"Transformação da superfície linguística em objeto discursivo":

Para efetuar esta transformação é necessário realizar uma pergunta norteadora: "O que é dito neste discurso? O que é dito em outro discurso?"

A partir de tal estruturação, expõe-se o objeto discursivo a partir dos fenômenos linguísticos discursivos (paráfrase, polissemia, polifonia) que incidem sobre ele.

"Do objeto discursivo para o processo discursivo":

Momento em que a pergunta norteadora é: “Por que isso e não outro?”. Na resposta em cada análise será atingido o processo discursivo, que mostra a relação que aquele dizer tem com o seu exterior.

Pode-se deste modo compreender as definições para Ciência da Informação e de que forma interagem com o histórico percorrido pela área no Brasil.

\subsection{ANÁLISE E DISCUSSÃO DOS RESULTADOS}

Por meio das bases teóricas e metodológicas da Análise do Discurso de matriz francesa foram analisados um total de vinte e oito artigos.

Quadro 1: Analise comparativa entre conceitos

\begin{tabular}{|c|c|c|c|c|}
\hline Ano & Períodico & Autor(es) & Artigo & Definição \\
\hline 1972 & $\begin{array}{l}\text { Ciência da } \\
\text { Informação }\end{array}$ & $\begin{array}{l}\text { C. R. Zaher e H. } \\
\text { E. Gomes. }\end{array}$ & $\begin{array}{l}\text { Da bibliografia à Ciência da } \\
\text { Informação: Um histórico e uma } \\
\text { posição }\end{array}$ & $\begin{array}{l}\text { Disciplina científica que considera a Bibliografia, } \\
\text { Biblioteconomia e Documentação como } \\
\text { suscetíveis de aplicar os resultados de suas } \\
\text { investigações; Ciência da Informação como } \\
\text { aquela que "investiga as propriedades e o } \\
\text { comportamento da informação, as forças que } \\
\text { regem seu fluxo e os métodos de processá-las para } \\
\text { acessibilidade e utilização ótimas"; } \\
\text { Atividade interdisciplinar. }\end{array}$ \\
\hline 1972 & $\begin{array}{l}\text { Ciência da } \\
\text { Informação }\end{array}$ & G. M. Braga & $\begin{array}{l}\text { Relações bibliométricas entre a } \\
\text { frente de pesquisa (Research Front) } \\
\text { e Revisões da Literatura: um } \\
\text { estudo aplicado à Ciência da } \\
\text { Informação }\end{array}$ & $\begin{array}{l}\text { Disciplina que diz respeito aos fenômenos de } \\
\text { comunicação. }\end{array}$ \\
\hline 1973 & $\begin{array}{l}\text { Ciência da } \\
\text { Informação }\end{array}$ & $\begin{array}{l}\text { L. M. } \\
\text { Figueiredo }\end{array}$ & $\begin{array}{l}\text { Distribuição da Literatura } \\
\text { Geológica Brasileira: um estudo } \\
\text { bibliométrico }\end{array}$ & Ciência baseada nos fundamentos da bibliometria. \\
\hline 1973 & $\begin{array}{l}\text { Ciência da } \\
\text { Informação }\end{array}$ & A. C. Dias & $\begin{array}{l}\text { Futorologia - Doença infantil da } \\
\text { Biblioteconomia }\end{array}$ & Disciplina de caráter puramente científico. \\
\hline
\end{tabular}



$1973 \begin{aligned} & \text { Ciência } \\ & \text { Informação }\end{aligned} \quad \begin{aligned} & \text { E. Lima e S. } \\ & \text { Maia }\end{aligned}$

1974 Revista da Escola de Biblioteconomi a da UFMG

1974 Revista da Escola de Biblioteconomi a da UFMG

\begin{tabular}{|l|l|}
\hline 1974 & $\begin{array}{l}\text { Revista da } \\
\text { Escola de } \\
\text { Biblioteconomi } \\
\text { a da UFMG }\end{array}$ \\
\hline 1974 & $\begin{array}{l}\text { Revista da } \\
\text { Escola de } \\
\text { Biblioteconomi } \\
\text { a da UFMG }\end{array}$ \\
\hline 1976 & $\begin{array}{l}\text { Revista da } \\
\text { Escola de } \\
\text { Biblioteconomi } \\
\text { a da UFMG }\end{array}$ \\
\hline
\end{tabular}

E. N. Fonseca

A pós graduação Biblioteconomia

Las ciencias de informacion en la escuela de bibliotecologia estudantes de

G. M. Braga escueta de bibliotecologia

M. L. B.

Carvalho, M. $\mathrm{H}$

A. Magalhães e

M. L.

Alphonsus

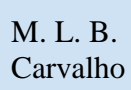

M. L. B.

Carvalho

Ciência interdisciplinar na medida em que a relaciona, neste caso, com Linguística e Bibliometria.

Ciência que refina os processos, sistemas e fenômenos da Biblioteconomia. língua portuguesa como veículo representação da informação

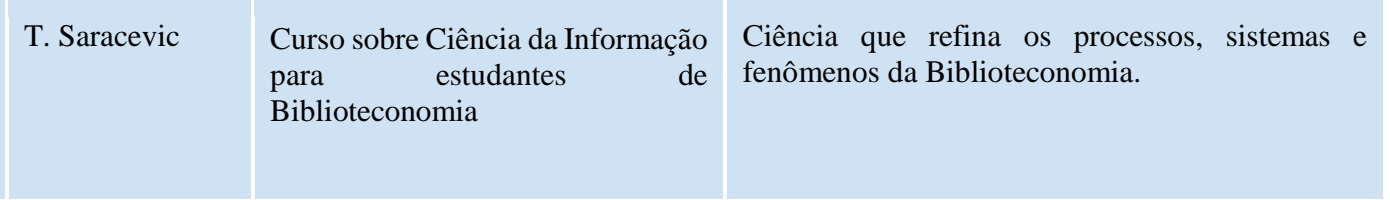

Ciência interdisciplinar que investiga as propriedades e comportamento da informação.

$1978 \begin{aligned} & \text { Revista da } \\ & \text { Escola de } \\ & \text { Biblioteconomi } \\ & \text { a da UFMG }\end{aligned}$

$1978 \begin{aligned} & \text { Ciência da } \\ & \text { Informação }\end{aligned}$

1981 Ciência da Informação
T. Saracevic

A. O. Carvalho

Pós-graduação em

Biblioteconomia e Ciência da

Informação: reflexões, sugestões, experiências

Educação em Ciência da Informação na década de 1980

M. N. F. Pereira

Geração, Comunicação e absorção do conhecimento científicotecnológico em sociedade dependente; um estudo de caso: o programa de engenharia química CQPPE/UFRJ 1963-1979

\begin{tabular}{|l|l|l|}
1982 & $\begin{array}{l}\text { Revista da } \\
\text { Escola de } \\
\text { Biblioteconomi } \\
\text { a da UFMG }\end{array}$ & J. Kremer \\
\hline 1982 & $\begin{array}{l}\text { Ciência da } \\
\text { Informação }\end{array}$ & $\begin{array}{l}\text { M. P. L. } \\
\text { Rodrigues }\end{array}$ \\
\hline
\end{tabular}

Ética e pesquisa: um tema para reflexão

Citações nas dissertações de mestrado em Ciência da Informação
Ciência interdisciplinar que relaciona a prática profissional com a pesquisa científica.

Produto do homem; Trabalho científico sobre a realidade social.

Ciência social.

Estudo dos fenômenos da comunicação, propriedades, comportamento e circulação da informação. 


\begin{tabular}{|c|c|c|c|c|}
\hline 1987 & $\begin{array}{l}\text { Revista da } \\
\text { Escola de } \\
\text { Biblioteconomi } \\
\text { a da UFMG }\end{array}$ & $\begin{array}{l}\text { N. A.. B. Foresti } \\
\text { e M. S. M. } \\
\text { Martins }\end{array}$ & $\begin{array}{l}\text { Revistas brasileiras de } \\
\text { Biblioteconomia, Documentação e } \\
\text { Ciência da Informação: } \\
\text { produtividade dos autores no } \\
\text { período de } 1980 \text { a } 1985\end{array}$ & $\begin{array}{l}\text { Estudo dos fenômenos da comunicação, } \\
\text { comportamento, propriedades, efeitos e processos } \\
\text { da informação. }\end{array}$ \\
\hline 1987 & $\begin{array}{l}\text { Ciência da } \\
\text { Informação }\end{array}$ & R. B. Cianconi & Banco de dados de acesso público & Ciência da organização da informação. \\
\hline 1988 & $\begin{array}{l}\text { Ciência da } \\
\text { Informação }\end{array}$ & R. Bouche & $\begin{array}{l}\text { Ciência da Informação; Ciência da } \\
\text { Forma }\end{array}$ & Ciência da organização da informação. \\
\hline 1992 & $\begin{array}{l}\text { Revista da } \\
\text { Escola de } \\
\text { Biblioteconomi } \\
\text { a da UFMG }\end{array}$ & $\begin{array}{l}\text { S. P. Mostafa e } \\
\text { E. I. M. } \\
\text { Marañon }\end{array}$ & $\begin{array}{l}\text { O segredo, a informação e a } \\
\text { cidadania }\end{array}$ & Ciência social. \\
\hline 1993 & $\begin{array}{l}\text { Ciência da } \\
\text { Informação }\end{array}$ & S. P. Mostafa & $\begin{array}{l}\text { Novos referencias teóricos no XVI } \\
\text { Encontro Nacional dos Estudantes } \\
\text { de Biblioteconomia }\end{array}$ & $\begin{array}{l}\text { Ciência que cuida dos fluxos e propriedades da } \\
\text { informação; ciência mais tipicamente pós- } \\
\text { moderna das ciências. }\end{array}$ \\
\hline 1995 & $\begin{array}{l}\text { Ciência da } \\
\text { Informação }\end{array}$ & H. T. Christovão & $\begin{array}{l}\text { A ciência da informação no } \\
\text { contexto da pós-graduação do } \\
\text { IBICT }\end{array}$ & $\begin{array}{l}\text { Característica interdisciplinar, uma conexão com } \\
\text { a tecnologia da informação além de papel social. }\end{array}$ \\
\hline 1995 & $\begin{array}{l}\text { Ciência da } \\
\text { Informação }\end{array}$ & G. M. Braga & $\begin{array}{l}\text { Informação, ciência da } \\
\text { informação: breves reflexões em } \\
\text { três tempos }\end{array}$ & Ciência interdisciplinar. \\
\hline 1995 & $\begin{array}{l}\text { Ciência da } \\
\text { Informação }\end{array}$ & $\begin{array}{l}\text { L. V. R. } \\
\text { Pinheiro e J. M. } \\
\text { M. Loureiro. }\end{array}$ & $\begin{array}{l}\text { Traçados e limites da ciência da } \\
\text { informação }\end{array}$ & $\begin{array}{l}\text { Ciência interdisciplinar; ciência que investiga as } \\
\text { propriedades e comportamentos da informação; } \\
\text { tem foco no usuário e que possui aplicações } \\
\text { tecnológicas. }\end{array}$ \\
\hline 1996 & $\begin{array}{l}\text { Perspectivas } \\
\text { em Ciência da } \\
\text { Informação }\end{array}$ & $\begin{array}{l}\text { R. M. Q. } \\
\text { Nehmy, C. H. R. } \\
\text { Falci, J. G. } \\
\text { Acosta e R. R. } \\
\text { Fraga }\end{array}$ & $\begin{array}{l}\text { A ciência da informação como } \\
\text { disciplina científica }\end{array}$ & $\begin{array}{l}\text { Deve fazer parte ou aproximar-se das disciplinas } \\
\text { que compõem as ciências sociais, além de ciência } \\
\text { interdisciplinar e pós-moderna. }\end{array}$ \\
\hline 1996 & $\begin{array}{l}\text { Ciência da } \\
\text { Informação }\end{array}$ & T. Saracevic & $\begin{array}{l}\text { Ciência da informação: origem, } \\
\text { evoluções e relações }\end{array}$ & $\begin{array}{l}3 \text { características gerais que constituem a da } \\
\text { evolução da C.I.: ciência interdisciplinar por } \\
\text { natureza; inexoravelmente ligada a tecnologia e } \\
\text { uma participante ativa e deliberada na evolução da } \\
\text { sociedade da informação, ou seja, ciência social. }\end{array}$ \\
\hline 1996 & $\begin{array}{l}\text { Perspectivas } \\
\text { em Ciência da } \\
\text { Informação }\end{array}$ & $\begin{array}{l}\text { M. Eugênio, R. } \\
\text { França e R. C. } \\
\text { Perez }\end{array}$ & $\begin{array}{l}\text { Ciência da Informação sob a ótica } \\
\text { paradigmática de } \\
\text { Thomas Kuhn: elementos de } \\
\text { reflexão }\end{array}$ & $\begin{array}{l}\text { Ciência que investiga as propriedades e } \\
\text { comportamento da informação e pode ser } \\
\text { considerada uma ciência aplicada. }\end{array}$ \\
\hline 1996 & $\begin{array}{l}\text { Perspectivas } \\
\text { em Ciência da } \\
\text { Informação }\end{array}$ & $\begin{array}{l}\text { A. M. P. } \\
\text { Cardoso }\end{array}$ & $\begin{array}{l}\text { Pós-modernismo e informação: } \\
\text { conceitos complementares? }\end{array}$ & $\begin{array}{l}\text { Disciplina que investiga as propriedades e } \\
\text { comportamento da informação, as forças que } \\
\text { governam seu fluxo; ciência interdisciplinar; } \\
\text { ciência pós-moderna e características de } \\
\text { transformação sociocultural. }\end{array}$ \\
\hline 1998 & $\begin{array}{l}\text { Ciência da } \\
\text { Informação }\end{array}$ & $\begin{array}{l}\text { R. M. Q. Nehmy } \\
\text { e I. A. Paim }\end{array}$ & $\begin{array}{l}\text { A desconstrução do conceito de } \\
\text { 'qualidade de informação }\end{array}$ & Disciplina da área de humanidades. \\
\hline
\end{tabular}


Fonte: Elaborado pelos autores

A Figura 1 demonstra a quantidade de artigos encontrada por década.

Figura 1: Quantidade artigos por década

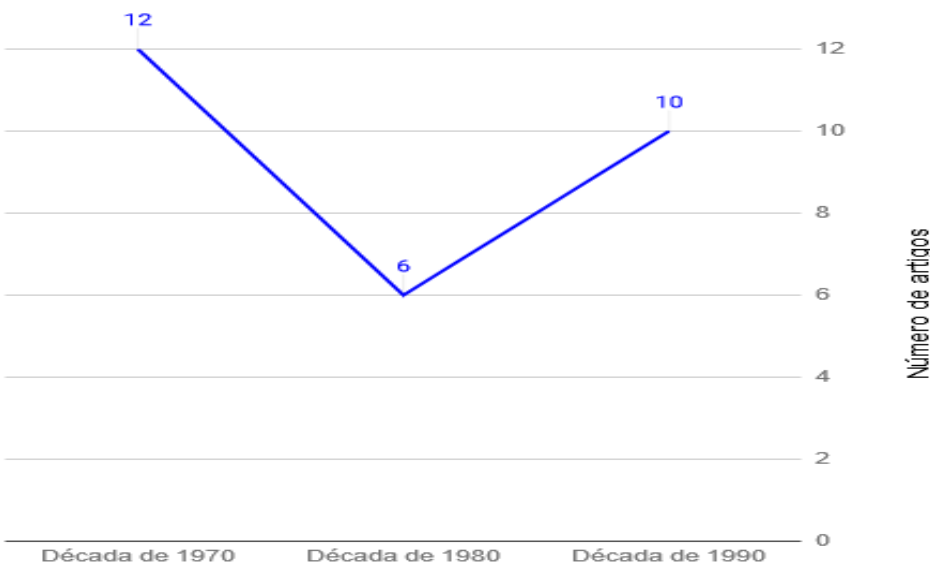

Fonte: Elaborada pelos autores

A década de 1970 com doze artigos analisados caracteriza-se como uma época em busca de consolidação epistemológica da área. Neste momento, a área esbarra frequentemente no conceito de interdisciplinaridade e ressalta as características de disciplina recente que carece de balizas teóricas.

Em 1980 há uma baixa incidência de artigos voltados para a definição do termo "Ciência da Informação". As instituições centravam esforços no desenvolvimento científico e tecnológico, tendo um maior número de publicações voltadas a estudos de uso e usuários, organização de coleções, ações culturais para bibliotecas públicas, comportamento e desempenho do profissional da informação. Ainda assim, foram encontrados seis artigos. Destes seis, cinco traziam uma definição apenas como um ponto introdutório e não como a preocupação central do texto. Caprioli (2016, p. 35) enfatiza que a pós-graduação brasileira na década de 1980 perde o impulso e o retoma apenas em 1990 com a criação de doutorados e novos cursos de mestrado.

O período de 1990 é marcado pela retomada das definições clássicas de interdisciplinaridade e ciência social que permeiam a área. Lima (2015, p. 14) explica que o discurso científico da Ciência da Informação é permeado por "[...] uma constante redefinição e repetição de posturas anteriores e de deslocamentos provocados pela ação do poder (instituições de pesquisa, pesquisadores, agências de fomento, universidades), e é parte do próprio movimento de validação científica"

O gráfico abaixo compila a incidência de definições encontradas. Percebe-se que há discrepância entre as definições acerca da área, ou seja, não há um equilíbrio epistemológico acerca do que seria a Ciência da Informação mas sim, dois polos: o que encara a ciência da informação como interdisciplinar sem grandes aprofundamentos sobre como se dá tal fenômeno, e por fim o polo que vê na epistemologia da Ciência da Informação um papel social de capaz de transformar realidades. Ou seja, a primeira definição é mais abstrata 
e teórica enquanto a segunda busca mostrar a responsabilidade sociocultural que a Ciência da Informação têm diante da sociedade sendo assim mais concreta

Figura 2: Sistematização das definições.

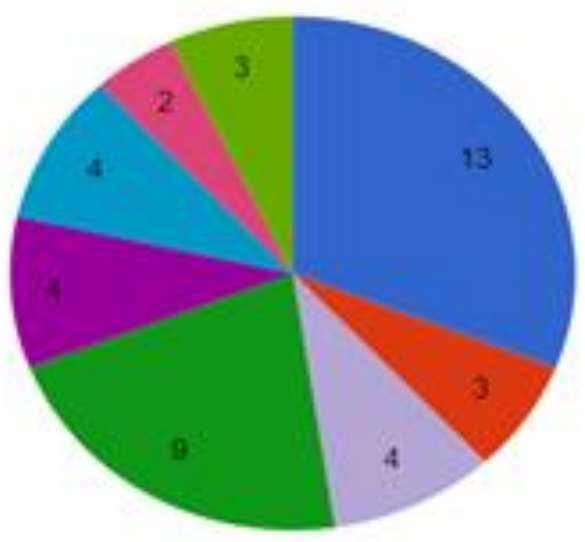

- Ciencia interdisciplinar - Ciência pós-moderna e Ciencia Social Disciplina que imvestiga as propriedades, fuxos, comportamento da informaçà

- Relaciona-serOtimiza a Bibliografia, Biblioteconomia e Documentacào

- Relaciona-se com a Comunicacão e Relaciona-se com a Biblometria - Papel socialtransformaçào socioculturalirealidade social

Fonte: elabora pelos autores

A conjuntura histórica da Ciência da Informação no Brasil é estrutura pelo viés institucional denominados por Lima (2015, p. 31) de instâncias de validação científica que moldam e determinam o caminho da área. Pinheiro (2013, p. 8) afirma que enquanto na Europa, a Ciência da Informação se desenvolve nas sociedades científicas (por exemplo, a Royal Society, na Inglaterra, e a Academie des Sciences, na França), no Brasil a mesma passa a existir nas universidades com os seus cursos de pós-graduação por intermédio destas figuras de validação científica.

Figura 3 - Instâncias de Validação Científica da Ciência da Informação no Brasil 


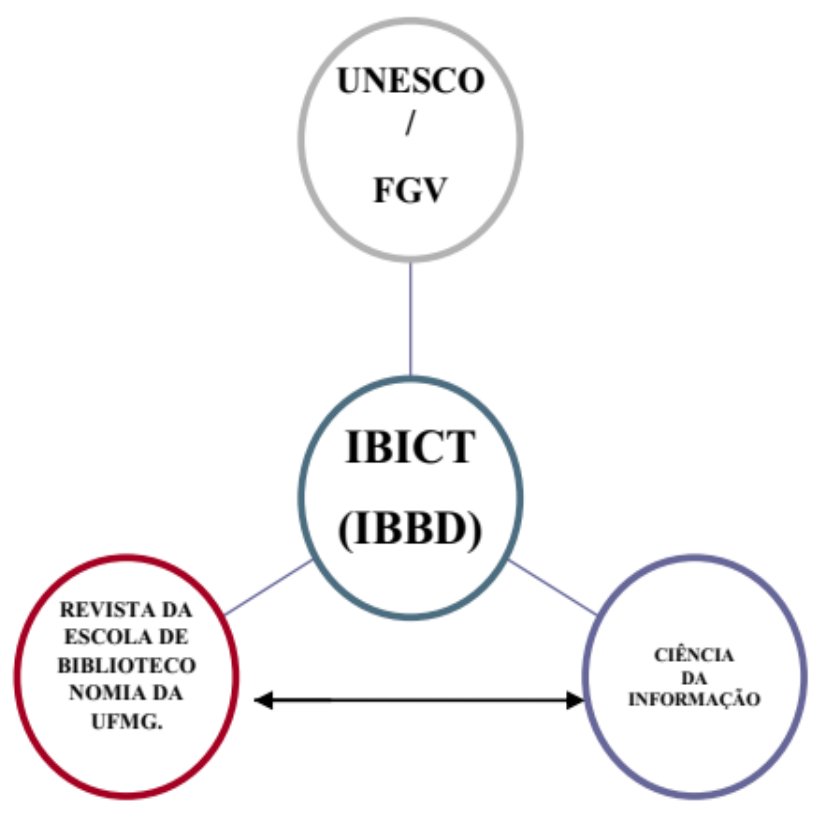

Fonte: Elaborada pelos autores

Pode-se, desta forma, verticalizar o discurso teórico advindo da Ciência da Informação nas décadas de 1970, 1980 e 1990 por meio dos seus periódicos.

\section{CONSIDERAÇÕES FINAIS}

A Ciência da Informação emerge como um paradigma que via na área uma explicação para as dificuldades informacionais e tecnológicas que a Biblioteconomia e a Documentação tradicionais não mais elucidavam, vemos tal perspectiva no segundo polo do gráfico acima que visa mostrar a responsabilidade social da Ciência da Informação, enquanto o primeiro polo fica em torno da questão da interdisciplinaridade assumindo uma roupagem mais abstrata e teórica.

O conceito de interdisciplinaridade foi proposto por Borko (1968), e mostra que a área perpassa por outras tantas para que haja um sentido ou uma definição, e é possível perceber que essa definição esclarece as discussões epistemológicas, pois a encara como fator chave para a consolidação da área e determinam uma formação discursiva, atravessando-a com outra formação discursiva.

Já a definição de que a Ciência da Informação se trata de uma ciência social, torna a definição do conceito mais completa e inteligível, além de se configurar no discurso de Saracevic (1996) de que é um campo dedicado à pratica profissional voltada para problemas de comunicação do conhecimento e seus registros entre os humanos, no contexto social expressamente dito. A aproximação da área a Comunicação ocorre devido a ambas terem características em comum como a interdisciplinaridade, a diversidade e atuação na esfera da informação e do conhecimento (FREIRES, 2007, p. 133).

Destaca-se que o curso de mestrado em Ciência da Informação teve a participação de professores estrangeiros oriundos principalmente dos Estados Unidos de modo que suas teorias, definições e crenças reverberaram no meio acadêmico brasileiro (PINHEIRO,1997, p. 87). 
Com o presente artigo, buscou-se delinear o percurso conceitual e discursivo da Ciência da Informação no Brasil durante as décadas de 1970, 1980 e 1990, por meio da análises de artigos presentes em periódicos da área. Utilizou-se a Análise do Discurso de matriz francesa como aporte teórico e metodológico para evidenciar os jogos de enunciado e posições ideológicas presentes na área.

O que se pode ressaltar é que observando os artigos dos anos 1970, fica possível dizer que a institucionalização histórico-discursiva da área se estruturou mediante formações discursivas que buscam sedimentar o conceito de interdisciplinaridade, mas também o fato da área ser recente, necessitando de bases teóricas bem definidas.

No período da década de 1980, a Ciência da Informação segue temáticas em voga da época que ressaltam o alinhamento aos planos governamentais de desenvolvimento científico e tecnológico. São escassos os artigos que definem a Ciência da Informação e os que o fazem tendem para três pontos: a) ciência social; 2 . Disciplina que aborda características da informação e; c) área próxima à Comunicação.

Enquanto que na década de 1990 volta a se destacar o conceito de interdisciplinaridade, mostrando a consolidação das bases da área, mas também surge o destaque da Ciência da Informação como uma ciência social, tornando a definição do conceito mais completa e inteligível, além de se configurar no discurso da década, visto que a Saracevic traz uma nova definição em 1996, como visto.

O emprego da Análise do Discurso de matriz francesa nos artigos analisados possibilitou conhecer o discurso construído acerca da Ciência da Informação brasileira. Nota-se que a área evidencia discursos mais proferidos, carrega certa discrepância entre as décadas e pende para uma instabilidade em se definir.

\section{REFERÊNCIAS}

BRANDÃO, H. H. N. Introdução à análise do discurso. 2a. ed. rev. Campinas: Editora da UNICAMP, 2004. BUSCHMAN, J. Transgredir ou estagnar? Desafiando Foucault na teoria da Biblioteconomia e Ciência da Informação. InCID: Revista de Ciência da Informação e Documentação. v.1, n.1, 2010.

CAPRIOLI, M. S. O percurso discursivo da Ciência da Informação por meio de estudo de periódicos da área na década de 1990. 2016, 68f. Trabalho de Conclusão de Curso (Graduação em Biblioteconomia) Faculdade de Filosofia e Ciências de Marília, Universidade Estadual Paulista, 2016.

CORDEIRO, P. A. C. Análise do discurso e ciência da informação: ensaio sobre uma possibilidade metodológica. 2004. 93f. Dissertação (Mestrado em Ciência da Informação) - Universidade Federal do Rio de Janeiro, Rio de Janeiro, 2004.

FREIRE, I. M. Informação; consciência possível; campo. Um exercício com construtos teóricos. Ciência de Informação. v.24, n. 1, p.133-142,jan./abr., 1995.

FREIRES, T. G. S. Relações entre a Ciência da Informação e as Ciências da Comunicação: um estudo dos conceitos de representação documentária, mediação e comunicação científica. 2007. 202 f. Trabalho de Conclusão de Curso (Graduação em Biblioteconomia) - Escola de Comunicações e Artes, Universidade de São Paulo, São Paulo, 2007. 
FREITAS, Lídia Silva de. Na teia dos sentidos: análise do discurso da Ciência da Informação sobre a atual condição da informação. 2001. 244f. Tese. (Doutorado em Ciências da Comunicação) - Escola de Comunicação e Artes - USP, São Paulo. São Paulo, 2001.

FREITAS, L. S. Entre o público e o privado: trajeto temático-discursivos da área da informação. Informação \& Sociedade. v.14, n.1, jan./jun.,2004

FREITAS, L. S. A análise do discurso e o campo informacional: usos atuais e alcance epistemológico: uma atualização. InCID: Revista de Ciência da Informação e Documentação. v.1, n. 1, 2010.

FOUCAUlT, M. An Interview with Michel Foucault. In: Faubion, James D., ed., Power. New York: The New Press, 1994. v 3. p. 239-97.

GREGOLIN, M. R. A análise do discurso: conceitos e aplicações. São Paulo: Alfa, 1995.

GREGOLIN, M. R. Foucault e Pêcheux na análise do discurso. São Carlos, SP: Claraluz, 2006.

HENRY, P. Os fundamentos teóricos da "análise automática do discurso" de Michel Pêcheux (1969). In: GADET, F.; HAK, T. (Orgs.) Por uma análise automática do discurso: uma introdução à obra de Michel Pêcheux. 3 ed. Campinas: Editora da UNICAMP, 1997. p. 13.

LIMA, L.M. O percurso discursivo da Ciência da Informação no Brasil: uma análise discursiva a partir dos periódicos Ciência da Informação e Revista da Escola de Biblioteconomia da UFMG. 2015. Trabalho de Conclusão de Curso (Graduação em Biblioteconomia) - Faculdade de Filosofia e Ciências de Marília, Universidade Estadual Paulista, 2015.

MAINGUENEAU, D. Novas tendências em análise do discurso. Campinas: Pontes, 1997.

ODDONE, N. E. O IBBD e a informação científica: uma perspectiva histórica para a ciência da informação no Brasil. Ciência da Informação. v. 35, n. 1. 2006.

ORLANDI, E.L.P. Análise de discurso: princípios e procedimentos. Campinas: Pontes, 1999.

ORLANDI, E. L. P. Discurso e leitura. 5. ed. São Paulo: Editora da Unicamp, 2000.

PINHEIRO, Lena Vânia Ribeiro. Ciência da Informação entre sombra e luz: domínio epistemológico e campo interdisciplinar. 1997. 278 f. Tese (Doutorado em Comunicação e Cultura) - Universidade Federal do Rio de Janeiro, Rio de Janeiro, 1997.

SARACEVIC, T. Ciência da Informação: origem, evolução e relações. Perspectivas em Ciência da Informação, Belo Horizonte, v. 1, n. 1, p. 41-62, jan.jun., 1996.

SAUSSURE, F. Course in General Linguistics. McGraw-Hill Book Company, 1966. 